\title{
Excelência em cirurgia de cristalino
}

$\mathbf{S}$ egundo Aurélio, excelência equivale à qualidade de excelente, que por sua vez significa muitíssimo bom, excepcional, excelso e que, em linguagem de marketing é conhecido como "padrão ouro".

Em 2009, ao falarmos em excelência em cirurgia do cristalino, nos referimos a todo o processo, desde o diagnostico, a indicação ou não de cirurgia, os exames oftalmológicos complementares, as técnicas e tecnologias empregadas, o ambiente onde é realizada a cirurgia, o pós-operatório e o resultado final.

A consulta oftalmológica é o inicio desse processo e a valorização da queixa do paciente deve ser explorada ao máximo e quando associada aos achados do exame da biomicroscopia do segmento anterior poderá ser de fundamental importância para a condução da terapêutica, que nos dias que correm deve ser a mais personalizada possível. Devemos reconhecer os fatores de risco cirúrgico para aplicar a estratégia adequada e, o diagnostico da associação de outras doenças oculares devem ser discutidas com o paciente a fim de se ter uma expectativa real de resultado.

Entre os exames pré-operatórios oftalmológicos devemos destacar a avaliação da retina central, periférica e vítreo, a avaliação do endotélio corneano através da microscopia especular e da biometria, para a qual devemos utilizar o método da interferometria óptica com fórmulas de $4^{a}$ geração como a Holladay II e Haigis. Situações especiais como cirurgias refrativas corneanas prévias e a presença de astigmatismo tem protocolos biométricos apropriados e em evolução.

Com o objetivo de oferecer o melhor resultado visual e refracional e com a possibilidade de um ajuste refrativo no pós-operatório através de cirurgia refrativa corneana, a avaliação da topografia corneana, a paquimetria topográfica e a aberrometria podem ser necessárias. Situações especiais podem exigir propedêutica especial com exames por imagem como os dados fornecidos pelo sistema de Scheimpflug, OCT do segmento anterior ou UBM.

Os testes funcionais da visão, associados ou não, podem fornecer informações interessantes, assim, a acuidade visual pelo teste de Snellen associada ao teste de sensibilidade ao contraste e o potencial de visão podem auxiliar na indicação e no prognostico visual. Em situações de dúvida diagnóstica, ou médicolegais em relação à opacificação do cristalino, a utilização da densitometria pelo sistema de Scheimpflug ou similar podem auxiliar no diagnóstico e quando houver alterações no diâmetro pupilar a pupilometria poderá ser de grande ajuda.

A técnica cirurgia será realizada com anestesia local, tópica ou injetável de acordo com as características de cada caso e das preferências do cirurgião.

A microincisão, $\leq 2.20 \mathrm{~mm}$, corneana com capsulotomia de 5.0 a $5.5 \mathrm{~mm}$ e a utilização de técnicas de chop com ultra-som de baixos parâmetros é a tônica. A facoemulsificação ultra-sônica não longitudinal com baixos valores de fluxo e de ultra-som, a diminuição da altura do liquido de infusão e os baixos parâmetros de vácuo tem resultado em cirurgias mais seguras e recuperação mais efetiva. A estes conceitos devemos acrescentar a utilização de viscoelastico que facilite a técnica e proteja os tecidos do segmento anterior.

A escolha da lente intra-ocular, prerrogativa do cirurgião em beneficio do paciente, terá como objetivo oferecer a melhor visão funcional possível e para atingir este objetivo existem as lentes asféricas, tóricas, multifocais, de microincisão ..., segmento em constante evolução.

A cirurgia do cristalino pode, hoje, ser realizada em sistema de alta imediata, porém este conceito deve seguir rigorosos protocolos de procedimento devido a cirurgia ser invasiva e num órgão cujo comprometimento funcional poderá afetar, em muito a qualidade de vida do paciente (risco/beneficio). O controle biológico periódico do centro cirúrgico faz parte do protocolo de prevenção de infecção.

A utilização de medicamentos tópicos no pré e pós-operatório é mandatória; daí o uso de antibiótico como fluorquinolona de última geração (prevenção de infecção) associado a antiinflamatório não hormonal (prevenção de inflamação, dor e coadjuvante na midríase per cirúrgica) e antiinflamatório 
hormonal (prevenção da inflamação do segmento anterior e posterior). Não podemos esquecer que o uso de lubrificante ocular também tem um papel importante na recuperação pós-cirurgia do segmento anterior em pessoas idosas em especial do sexo feminino. São coadjuvantes imprescindíveis para um resultado final com padrão de excelência.

Ao atingir o resultado funcional satisfatório no primeiro olho não podemos nem devemos postergar a realização da cirurgia no segundo olho, quando esta for indicada, pois assim a recuperação funcional estará completa. $\mathrm{O}$ intervalo deverá ser aquele que o cirurgião, com base à evidencias científicas, à sua experiência e às necessidades do paciente, avalie ter o maior beneficio com o menor risco para o paciente.

Todo este processo que envolve a arte do relacionamento interpessoal, utilização de alta tecnologia e de técnicas de custoso aprendizado deve vir acompanhado da educação e conscientização do paciente e familiares, da utilização rotineira do consentimento informado tendo como base as diretrizes da AMB e os direitos do consumidor.

Não devemos esquecer os aspectos socioeconômicos que envolvem a cirurgia do cristalino com o crescimento da população da terceira idade, conhecida como os "novos envelhecentes" ou baby boomers, que se apresenta como um grupo populacional ativo, informado, com perspectiva de vida maior e em especial com grande auto-estima.

Analisando todos os fatores até aqui expostos, me pergunto: como a cirurgia do cristalino pode ser banalizada? Quem irá pagar a conta desta excelência?

O importante é poder afirmar que o passado e presente colocaram a cirurgia do cristalino num patamar de excelência "nunca antes imaginado" e poder olhar o futuro com a convicção de que este nível de excelência não só será mantido como superado com a evolução natural da ciência.

IMO - Instituto de Moléstias Oculares - São Paulo (SP), Brasil 